\begin{tabular}{|c|l|}
\hline Title & Visual and olfactory input segregation in the mushroom body calyces in a basal neopteran, the A merican cockroach \\
\hline Author(s) & Nishino, Hiroshi; Iwasaki, Masazumi; Y asuyama, Kouji; Hongo, Hidenori; W atanabe, Hidehiro; Mizunami, Makoto \\
\hline Citation & $\begin{array}{l}\text { Arthropod Structure \& Development, 41(1), 3.16 } \\
\text { https://doi.org/10.1016/.asd.2011.08.005 }\end{array}$ \\
\hline Issue Date & 2012-01 \\
\hline Doc URL & http://hdl.handle.net/2115/48366 \\
\hline Type & article(author version) \\
\hline File Information & A SD41-1_3-16.pdf \\
\hline
\end{tabular}

Instructions for use 


\section{Visual and olfactory input segregation in the mushroom body calyces in a basal neopteran, the American cockroach}

Hiroshi Nishino ${ }^{* 1}$, Masazumi Iwasaki ${ }^{2}$, Kouji Yasuyama $^{3}$, Hidenori Hongo ${ }^{1}$, Hidehiro Watanabe $^{4} \&$ Makoto Mizunami ${ }^{2}$

${ }^{I}$ Research Institute for Electronic Science, Hokkaido University, Sapporo 060-0812, Japan, ${ }^{2}$ Graduate School of Life Sciences, Hokkaido University, Sapporo 060-0810, Japan, ${ }^{3}$ Department of Natural Sciences, Division of Biology, Kawasaki Medical School, Kurashiki, 701-0192, Japan, ${ }^{4}$ Faculty of Science, Fukuoka University, Fukuoka 814-0180, Japan

*Correspondence to be sent: Hiroshi Nishino, Research Institute for Electronic Science, Hokkaido University, Sapporo 060-0812, Japan.

Tel: +81-11-706-2596

Fax: +81-11-706-3446

Email: nishino@es.hokudai.ac.jp 


\begin{abstract}
The cockroach Periplaneta americana is an evolutionary basal neopteran insect, equipped with one of the largest and most elaborate mushroom bodies among insects. Using intracellular recording and staining in the protocerebrum, we discovered two new types of neurons that receive direct input from the optic lobe in addition to the neuron previously reported. These neurons have dendritic processes in the optic lobe, projection sites in the optic tracts, and send axonal terminals almost exclusively to the innermost layer of the MB calyces (input site of MB). Their responses were excitatory to visual but inhibitory to olfactory stimuli, and weak excitation occurred in response to mechanosensory stimuli to cerci. In contrast, interneurons with dendrites mainly in the antennal lobe projection sites send axon terminals to the middle to outer layers of the calyces. These were excited by various olfactory stimuli and mechanosensory stimuli to the antenna. These results suggest that there is general modality specific terminal segregation in the MB calyces and that this is an early event in insect evolution. Possible postsynaptic and presynaptic elements of these neurons are discussed.
\end{abstract}

Key Words: mushroom body; insects; neoptera; interneurons; protocerebrum; optic lobe

Abbreviations: ACT: antenno-cerebral tract; MB: mushroom body; OL: optic lobe; 1 ho: lateral horn; PN: projection neuron; T: tract. 


\section{Introduction}

Insect mushroom bodies (MBs) are bilaterally symmetrical structures in the brain, and are comprised of numerous small intrinsic neurons called Kenyon cells (Strausfeld, 1976). In addition to playing a critical role in olfactory learning (Erber et al., 1980; de Belle and Heisenberg, 1994; Krashes et al., 2007), MBs are also implicated in mediating or modulating some complex adaptive behaviors including visual context generalization (Liu et al., 1999), visual place learning (Mizunami et al., 1998d), choice behavior (Tang and Guo, 2001), courtship conditioning (McBride et al., 1999), and sleep (Joiner et al., 2006; Pitman et al., 2006).

Neuroanatomically, each Kenyon cell has dendrites in the calyx and an axon leading to the pedunculus (Schürmann, 1974; Strausfeld, 1976). The axon bifurcates into the vertically-oriented lobe (vertical lobe) and the medially-oriented lobe (medial lobe) (Strausfeld and Li, 1999a,b; Sjöholm et al., 2005), which are also known as the $\alpha$ and $\beta$ lobes, respectively. The Kenyon cell axons running in the different lobes form parallel layers, called slabs (Mizunami et al., 1998a,b) or laminae (Strausfeld and Li, 1999b; Farris and Strausfeld, 2001), which are reminiscent of columnar organization of the mammalian cortex (Mizunami et al., 1997; Farris and Roberts, 2005).

Generally, the most significant sensory input to the MB in neopteran insects is olfaction (Mobbs, 1982; Straufeld et al., 1998). Several hundred projection neurons (PNs), with dendrites in one or more olfactory glomeruli, send axons to calyces and the lateral horn ( $l$ ho) (e.g. Malun et al., 1993; Tanaka et al., 2004; Galizia and Rössler, 2010). Extrinsic neurons, which have dendrites in specific layers of the MB lobes, are known to exhibit multimodal responses to various sensory stimuli (Schildberger, 1984; Li and Strausfeld, 1997, 1999; Mizunami et al., 1998c; Okada et al., 1999), which suggests that sensory signals other than olfaction are delivered to the MB. For example, one or a few neuronal process (es) project from the optic lobe to the MB calyces in the cricket Gryllus campestris (Honegger and Schürmann, 1975), dragonfly Aeschna grandis (Svidersky and Plotnikova, 2004) and noctuid moth Spodoptera littoralis (Sjöholm et al., 2005).

Comparative studies have revealed that the proportion of the MB volume in the protocerebrum and the number of Kenyon cells largely differ between insects (e.g., 
Strausfeld et al., 2009). The elaboration of the MB is positively correlated with feeding ecology of insects and the degree of elaboration differs between even close species having different feeding ecology (Farris and Roberts, 2005). Hence, studies based on comparative view points are important for deeper understanding of the MB function and evolution.

The American cockroaches are basal neopteran insects, and the MB of the cockroach possesses conserved features (Farris and Strausfeld, 2003). Cockroaches are polyphagous, allowing to adapt to various habitats from forests to human residences. Possibly reflecting this, the adult cockroach is equipped with an elaborate MB containing about 200,000 Kenyon cells (Neder, 1959); the largest number reported so far among insects. The American cockroach is well-known by its excellent capability of olfaction (Boeckh and Ernst, 1987; Sakura et al., 2002) and olfactory learning (Sakura and Mizunami, 2001; Watanabe et al., 2003), but it also has the capability of vision and visual spatial learning (Mizunami et al., 1998c; Kwon et al., 2004; Brown and Strausfeld, 2009) and the use of visual context for selecting conditioned odors (Sato et al., 2006). In contrast to the abundant olfactory inputs to the MB calyces, only one neuronal process from the optic lobe to the MB calyces has previously been detected in the American cockroach (Strausfeld and Li, 1999a).

In this study, we investigated the morphology and physiology of identifiable interneurons with large cell bodies and thick neurites conveying multimodal signals to calyces using intracellular recordings and staining with the aim of providing new insights into the modality-specific segregation of the calyces. Complete optical sections of these neurons are available as supplementary movies.

\section{Materials and Methods}

\subsection{Animals and gross neuroanatomy}

Adult male cockroaches (P. americana) with intact antennae, reared in $12: 12 \mathrm{~h}$ light-dark cycle at $27^{\circ} \mathrm{C}$, were used. To stain axons of interneurons from the optic lobe, the right optic lobe, including the medulla and lobula regions, were punctured using an electrolytically sharpened tungsten needle. The optic lobe was dissected so 
that the remaining lobe tissue resembled a nerve; the lobe remnant could then fit in a glass capillary for staining. The distal cut-end of the medulla placed in the broken tip of a tapered glass electrode filled with microruby or microemerald (Invitrogen, USA). To visualize second-order olfactory centers, crystals of microemerald were inserted manually into the antennal lobe. To stain axonal bundles of the inner antenno-cerebral tract (IACT), crystals of microemerald were inserted manually into the IACT after the medial region of the protocerebrum was desheathed. The dyed specimens were incubated in a humid chamber at $4^{\circ} \mathrm{C}$ for $12-16 \mathrm{~h}$ after which the brain was dissected out and processed for confocal microscopic observations.

\subsection{Neurophysiology}

The methods for intracellular recording and staining were identical to those previously described (Nishino et al. 2003). Briefly, a borosilicate microelectrode pulled by a laser puller (Sutter, P2000) was filled with 8\% Lucifer Yellow (Sigma) in $1 \mathrm{M} \mathrm{LiCl}$. After anesthetizing with carbon dioxide, the cockroach was fixed onto an acrylic chamber, the brain was exposed, and an electrode was inserted into the lateral protocerebrum. The right antenna was positioned in the center of a custom-made glass tube (ID: $2 \mathrm{~cm}$ ) in which continuous air flow $(5 \mathrm{l} / \mathrm{min})$ passed. For odor stimulation, the air passed through one of nine stimulus cartridges (plus one for a blank), each containing a filter paper $(5 \times 40 \mathrm{~mm})$ soaked with $40 \mu 1$ odorant solution (natural odorants, fatty acid, and feces extract) was delivered to the glass tube containing the antenna, via silicone tubing (ID: $5 \mathrm{~mm}$ ). A solenoid valve was used to switch between olfactory stimuli so that the air flow rate did not change before and after stimulation. Residual air in the recording cage was continuously removed using a vacuum system. Tactile stimulation was applied to the antenna by using a thin metal pin extended from the sensor of a strain gauge (TB-612T, Nihon Kohden, Japan). An air puff stimulus was delivered to the cerci, and this was controlled by another solenoid valve. A sufficient interval ( $>1$ minute) was set between the same kind of stimuli to avoid sensory adaptation of neurons. For illumination of the compound eyes, optical fiber was used to transmit light from a green light-emitting diode to the compound eye. The luminance at the compound eye was $\sim 0.2 \mathrm{Wm}^{-2}$ during light stimulation. At the end of a recording session, the neuron was filled with 
Lucifer Yellow by applying hyperpolarizing current (-2 4 nA for 5 20 min).

\subsection{Confocal microscopy}

After removal from the head capsule, the brain was fixed in a $4 \%$ formaldehyde saline solution for $4 \mathrm{~h}$ at $5^{\circ} \mathrm{C}$, dehydrated in an ascending ethanol series, and then cleared in methyl salicylate. The cleared brain was viewed anteriorly using a confocal laser-scanning microscope (LSM5 Pascal, Carl Zeiss, Jena, Germany). Optical sections $(1 \sim 2 \mu \mathrm{m})$ of the primary neuropils in the right brain hemisphere were reconstructed three-dimensionally with Amira software (Visage imaging).

\subsection{Terminology}

All descriptions of neurons refer to the body axis to allow comparison with literature data. Accordingly, the three subdivisions of the $l$ ho: antero-ventral (a-v) $l$ ho, postero-ventral (p-v) $l$ ho and dorsal (d) $l$ ho relative to neuraxis (Nishino et al., 2003) were re-designated antero-dorsal (a-d) $l$ ho, antero-ventral (p-v) $l$ ho and posterior (p) $l$ ho. The "calycal neuropil" is defined as dendritic fields of Kenyon cells (Mobbs, 1982). The dendritic processes and axon terminals of intracellularly-stained neurons were readily distinguishable from their differing preand postsynaptic morphologies: the former exhibit many spines and the latter exhibit swollen, varicosity-rich terminal arborizations (Okada et al., 2003). As an additional criterion, the excitatory postsynaptic potential (EPSP) height and spike undershoot were used to confirm whether the recording site was from dendrites or from axon terminals, respectively (Nishino and Mizunami, 1998). The naming of neurons is based on the principal sensory modality to which they exhibited the strongest excitatory responses. These neurons were further classified into "types" according to their major morphological features. The physiological and morphological descriptions are from the following number of neurons each from different individuals: type 1 visual input: $\mathrm{N}=6$; type 2 visual input: $\mathrm{N}=2$; type 1 olfactory input: $\mathrm{N}=6$; type 2 olfactory input: $\mathrm{N}=8$; visual + olfactory input: $\mathrm{N}=1$. The neurons categorized into the same neuron type had almost identical morphologies. 


\section{Results}

\subsection{Gross morphology of brain neuropils and sensory tracts}

The three-dimensional reconstructions of the right brain hemisphere (Fig. 1A-C) in which microemerald was injected into the antennal lobe (green) show the MB calyces (magenta) the pedunculus/lobes (red) and the lateral horn (cyan) in addition to the lobula (orange) and medulla (yellow) of the optic lobe (orange from autofluorescence). The calycal neuropil of the MB has been further divided into zones I, II, III, and IIIA according to the locations of axon terminals from extrinsic interneurons (Fig. 1D, modified from Strausfeld and Li, 1999a).

Microemerald dye injection into the optic lobe revealed extensive projections of optic tracts in the ipsilateral protocerebrum. The seven optic tracts (T1-T7) reported in the cockroach Leucophaea maderae (Reischig and Stengl, 2002) were identifiable in $P$. americana (Fig. 2A-C). T7 bifurcates into the dorsal subtract (T7-1) and the ventral subtract (T7-2) in the lateral protocerebrum, which subsequently merge in the medial protocerebrum (Fig. 2C). The ipsilateral collaterals from the optic tracts were located in five separate regions. Firstly, the thick T1 tract projected almost exclusively to the anterior-most region, lateral to the base of the vertical lobe; an area corresponding to the anterior optic tubercle (AOTu, Fig. 2A). A few fibers bypassing the AOTu ran in the anterior surface toward the contralateral side of the brain (Reischig and Stengl, 2002). Second, thin axons forming the T2 gave rise to collaterals in the lateral accessory lobe (LAL, Fig. 2B). Third, T3 and 4 gave rise to collaterals immediately ventral to the base of the MB between the vertical lobe and the pedunculus (Fig. 2B). This region corresponds to the superior lateral protocerebrum (SLP, Reischig and Stengl, 2002). Fourth, axons forming T4, 5 and 6 gave rise to fine collaterals in the inferior lateral protocerebrum (Fig. 2B,C). Fifth, axons forming T4 and 7 supply a large number of collaterals posteriorly to the pedunculus and medial lobe of the MB (Fig. 2B,C). The T5 neuron, intracellularly stained, had collaterals in the ipsilateral inferior lateral protocerebrum and a fiber projecting to the contralateral brain hemisphere (Fig. 2D), whereas the T7-1 and T7-2 neuron axon terminals were localized in the posterior region of the protocerebrum (Fig. 2E, F). 
Observations using oil immersion objectives (x40) consistently revealed that there is a single type of neuronal process terminating exclusively in the innermost layer of the MB calyces (Fig.2G-I). Its localization and brush-like varicosities match those of visual input axons (Nishikawa et al., 1998). The origin of this type of neuron was not identifiable.

Differential staining of the optic tract and the inner antenno-cerebral tract (IACT; Malun et al., 1993) revealed segregation of the termination fields of optic tracts (green) and uniglomerular PNs (magenta) in the lateral protocerebrum (Fig. 2J-N). $\mathrm{T} 2$ follows the boundary between the a-d $l$ ho and the a-v $l$ ho (Fig. $2 \mathrm{~K}$ ).

\subsection{Presumed visual input neurons to the MB calyces}

\section{Type 1 neuron}

The cell body (circa. $30 \mu \mathrm{m}$ diameter) was located anteriorly between the lobula and medulla, close to the accessory medulla (aMe, Fig. 3A,B). This region contains another cell body with branches ipsilaterally in the superior lateral protocerebrum in addition to a contralateral fiber passing T3 (not shown).

A dendritic process, diverging from the cell body neurite, provided a few arborizations in the posterior region of the lobula (white arrow, Fig. 3C-E). Another thin dendritic process ran laterally, in parallel to the cell body neurite, and supplied branched endings in the accessory medulla (white arrowhead, Fig. 3C-E). Rich dendritic arborizations distributed in the optic tubercle and superior lateral protocerebrum appeared to overlap with the termination fields of optic tracts 1,3 , and 4. Sparse dendrites were distributed in the posterior region of the protocerebrum, and appeared to overlap the termination fields of optic tract 7-1 (see Fig. 2C). A thick axon loops the pedunculus (Fig. 3A,B) and gives rise to many axonal processes radially along the innermost layer of the calycal neuropil (Fig. 3F,G), where brush-like terminals were linked together (Fig. 3A,B). This axonal branching pattern and the specialized terminal morphologies exactly match those of visual input axons (Nishikawa et al., 1998). Movie of a confocal stack of a type 1 visual input neuron is available in Fig. 3-1.

This neuron showed constant spike discharge $(10 \sim 30 \mathrm{~Hz}$, varied in different neurons of the same type) in the dark. It exhibited complex responses to light stimuli 
(Fig. 3H). On initiating the light stimulus the spike activity rose initially, then decreased slightly to a higher level compared to the pre-stimulus activity for the remaining stimulus period. On ceasing the stimulus, spike activity decreased for about $250 \mathrm{~ms}$ concomitant with a hyperpolarization, then returned to the pre-stimulus level (Fig. 3H). It showed inhibitory responses, characterized by membrane hyperpolarization, to all odors (Fig. 3I-K). This neuron showed a slight increase of spike activity followed by a transient decrease in response to air puff stimuli to cerci (Fig. 3L).

\section{Type 2 neuron}

The cell body (circa. $30 \mu \mathrm{m}$ in diameter) was located in the postero-ventral region of the lateral protocerebrum (Fig. 4A,B), slightly medial to the cell bodies of the GABA-immunoreactive calycal giant neurons (Yamazaki et al., 1998). The dorsal neurite, running between the pedunculus and the vertical lobe, gave rise to dendritic arborizations in the antero-proximo-dorsal region of the lobula (black arrow, Fig. 4A), the superior lateral protocerebrum, and a region just dorsal to the antero-dorsal region of the protocerebral bridge (white arrowhead, Fig. 4A). The arborizations partly overlap with termination fields supplied by optic tracts 3 and 4 . The ventral neurite traversing medio-laterally in the posterior-most region of the protocerebrum gave rise to dendritic arborizations posterior to the central complex and the medial lobe (black arrowhead, Fig. 4A), and these partly overlapped the termination fields of optic tract 7-2 (see Fig. 2C). The axon terminals were distributed extensively in the calyces and sparsely in the lateral regions of the a-d lho and p lho (white arrows, Fig. 4A). Their brush-like terminal specializations, resembling those of type 1, were mostly distributed in the innermost layer of the calycal neuropil (Fig. 4C,D) with the remainder in the outer layer (white arrow, Fig. 4D). Movie of a confocal stack of a type 2 visual input neuron is available in Fig. 4-1.

This neuron showed irregular spike burst activity in the dark. In response to light it exhibited a transient increase of spike activity which soon habituated (upper trace, Fig. 4E), and cessation of the light stimulus caused a brief inhibition (Fig. 4E). The light response was much weaker in the second stimulus (lower trace, Fig. 4E) compared to the first. This neuron showed inhibitory responses with membrane hyperpolarization to all odors tested with variable latencies (Fig. 4F). It showed a 
brief excitatory response to the first air current stimulus to the cerci but no response to the second stimulus (Fig. 4G).

\subsection{Olfactory input neurons to the MB calyces}

\section{Type 1 neuron}

The cell body located in the antero-dorsal surface of the lateral protocerebrum is about $40 \mu \mathrm{m}$ in diameter (Fig. 5F,G), which is comparable to the cell body size of the GABA-immunoreactive calycal giants (Yamazaki et al. 1998; Nishino and Mizunami, 1998; Strausfeld and Li, 1999a). It's fine dendritic processes were distributed broadly in the diffuse neuropil situated antero-medially to the junction of the MB lobes (Fig. $5 \mathrm{~A}$ ) and in the antero-ventral region of the lateral protocerebrum (lower region, Fig. 5B). The dendrites close to the junction of the MB lobes appeared to overlap with the terminal arborizations of the medial lobe output neurons (Li and Strausfeld, 1999; Okada et al., 1999). The varicose axon terminals were located in the $l$ ho, the neuropil just ventral to the $\mathrm{p} l$ ho (directed by white arrow, Fig. 5D), which receive axon terminals of ACT II and III PNs (Malun et al., 1993), the posterior slope, and the MB calyces (Fig. 5C-E). Its axon terminals covered the whole $l$ ho except for the region occupied by the termination fields of the sex pheromone-receptive PNs (outlined by white broken line, Fig. 5B; Nishino et al., 2003) and type 2 uniglomerular PNs (outlined by white broken line, Fig. 5C; Strausfeld and Li, 1999a). In the calyces, axon terminals covered the middle to outer layer of the calycal neuropil but were absent from the tip (zone I) where type 2 uniglomerular PNs axon terminals are found (Fig. 5E,F; Li and Strausfeld, 1997; Strausfeld and Li, 1999a). Movie of a confocal stack of a type 1 olfactory input neuron is available in Fig. 5-1.

This neuron showed sporadic spike activity during continuous delivery of a clean air to an antenna $(0 \sim 5 \mathrm{~Hz})$. It exhibited an excitatory response to all odors tested and the response magnitudes were odor-specific. For example, fatty acid (n-caproic acid) and feces extract consistently evoked strong excitatory responses, while orange, banana, and rose odors evoked weaker responses (Fig. 5H). It also exhibited prominent excitatory responses to the air puff on the ipsilateral antenna (Fig. 5I) but showed weak inhibitory or lacked responses to the light stimuli (not shown). 


\section{Type 2 neurons}

This neuron type was comprised of 6-7 neurons with variably sized cell bodies $(20 \sim 35 \mu \mathrm{m})$ located in the antero-ventral region of the base of the optic lobe. As these axons were bundled, the neurons were often multiply stained in intracellular recordings (Fig. 6B). Branches of these neurons were seen in the $l$ ho (Fig. 6C), the superior lateral protocerebrum, and the calycal neuropil (Fig. 6D). These branches possessed both spiny and varicose processes, suggesting that input sites and output sites are intermingled.

We identified two morphologic subtypes intracellularly. As previously observed in the calycal giant neurons (Strausfeld and Li, 1999a), these neurons innervated different proximo-distal zones in the calyces. Subtype 1 had fine branches distributed in the superior lateral protocerebrum, the whole of $l$ ho (except for the termination fields of type 2 uniglomerular PNs and pheromone-receptive PNs), and in the zone II-IIIA of the calycal neuropil (Fig. 6A,E). Subtype 2 had branches in the superior lateral protocerebrum, the whole of $l$ ho, and in zone I of the calycal neuropil (Fig. 6F). A movie of a confocal stack of subtype 1 neuron is available in Fig. 6-1.

The subtype 1 neurons showed very low spontaneous spike activity $(<0.1 \mathrm{~Hz})$ and exhibited brief excitatory responses comprising one to several spikes to various olfactory stimuli (Fig. 6G). The responses were odor-specific with weak responses to orange and banana odor, and stronger responses to peppermint and apple odor (Fig. $6 \mathrm{G})$. The subtype 1 neurons did not show any detectable responses to light-on/off stimuli (not shown). Physiological responses of subtype 2 were not investigated.

\subsection{Visual + olfactory input neurons to the MB calyces}

The cell body (circa. $15 \mu \mathrm{m}$ diameter) was located in the postero-ventral region of the protocerebrum, close to that of the type 2 visual input neuron. The neuron had extensive branches in the optic lobe, the $l$ ho and superior lateral protocerebrum (Fig. 7), and the mid to outer layers of the calycal neuropil (Fig. 7A). Especially dense arborizations were seen in the medulla (except the accessory medulla), lobula, and $a-v l$ ho. All of these branches possessed both spiny and varicose processes, suggesting that input sites and output sites are intermingled. It showed very low spontaneous activity in during continuous delivery of a clean air and exhibited one to 
a few spikes to different odors. Visual stimuli were not tested.

\section{Discussion}

Using intracellular recording and staining techniques, we have identified new types of calycal input neurons which differ morphologically from the giant calyx afferent neurons and the two types of multimodal calycal afferent neurons reported in previous studies (Nishino and Mizunami, 1998; Strausfeld and Li, 1999a). Recordings from neurons in the present study showed they were all spiking interneurons, and their input/output sites were readily identifiable. The type 1 visual input neurons and type 1 olfactory input neurons have especially thick neurites and were frequently encountered in intracellular recordings from the lateral protocerebrum. Their size permitted up to $20 \mathrm{~min}$ of intracellular recordings, which makes them suitable as a new neuron model for elucidating higher-order visual and olfactory processing in the MB.

A novel finding in this study is that visual input and olfactory input were generally found in the innermost layer and in the mid to outer layers along the calycal neuropil, respectively (Fig. 8), in agreement with the functional subdivision of the calyces proposed by Nishikawa et al. (1998). Type 1 uniglomerular PNs rarely have axon terminals in the innermost layer of the calycal neuropil (Fig. 8F) and Type 2 and pheromone-receptive PNs had only a few terminals bound on the innermost layer (Nishino, preliminary observations). The mid to outer layers of the calycal neuropil are functionally further divided into the calycal tip (zone I) and the remaining regions (zone II, III, IIIA), which receive axon terminals from type 2 and type 1 uniglomerular PNs, respectively (Strausfeld and Li, 1999a; Fig. 8). Our study does not negate the possibility that further functional segregation occurs in layers or zones of the MB calyces in the cockroach. For example, PNs with dendrites in the dry-sensitive glomeruli possess axon terminals almost exclusively in the outer layer (Nishino et al., 2003). Subtype 2 of type 2 olfactory input neurons possessed branches covering zone I with fewer branches in the distal most (tip) region (Fig. $6 \mathrm{~F})$.

Olfactory and visual input segregation in the calyces has been detected in other insect species. Most prominently, in honeybees (Gronenberg, 2001: Ehmer and 
Gronenberg 2002) and ants (Gronenberg, 2001), axon terminals of olfactory and visual input neurons are localized in the lip and collar regions, respectively. In noctuid moths (Sjöholm et al., 2005), a single type of neuron sparsely branches in the inner layer of the calyx cup, which lacks antennal lobe innervation. In field crickets, some neuronal processes from the optic lobe project to the MB (Honegger and Schürmann, 1975). These studies, together with the present study, suggest that the sensory modality-specific segregation of the MB calyces is an early event in insect evolution.

The complete staining of presumed visual input neurons provides evidence of interneurons directly connecting the $\mathrm{OL}$ and the $\mathrm{MB}$ in cockroaches. The fine dendritic processes covered part of the medulla and/or the lobula. However, it should be emphasized that the density of these processes was much lower than that on the lateral protocerebrum (Figs. 2, 3), supporting the view that visual input to the MB is indirect (Strausfeld and Li, 1999a).

The conserved morphologies of theses two types of neurons between individuals suggest that there are no morphologic subtypes. Furthermore, dye injections into the OL consistently stained only a few neuronal processes in the innermost layer of the MB calyces (Fig. 2). Thus, we assume that neurons delivering visual signals directly from the $\mathrm{OL}$ to the $\mathrm{MB}$ are very few in the cockroach. This contrasts with hymenopteran insects in which direct visual input from the optic lobe to the MB is more substantial (Gronenberg, 2001; Ehmer and Gronenberg, 2002). This difference is at least partly attributable to their different behavioral ecologies: cockroaches are nocturnal and thus rely more heavily on chemosenses, whereas social hymenopterans such as honey bees or ants are generally diurnal and rely on visual and chemosensory information. In fact, a comparative morphometric analysis revealed that the cockroach $L$. Maderae has relatively smaller optic lobes but the largest AL and MB among species studied, including honey bees and fruit-flies (Wei et al., 2010).

Dendrites from the two types of visual input neurons appeared to overlap greatly with projection sites of optic lobe tracts (Figs. 3,4). The dendritic locations of the two types of neurons were generally segregated; the dendrites of type 1 visual input neurons were mainly distributed in the anterior protocerebrum, largely overlapping with collateral branches of the anterior optic tract (T1), while dendritic fields of type 2 visual input neurons were distributed in the posterior protocerebrum which include 
projection sites of the posterior optic tract (T7). Therefore, visual input neurons are likely specialized for processing signals from particular subsets of optic tract neurons. In the bumble bee, all visual input neurons supplying the calyces are known to be color sensitive while a subset is motion sensitive (Paulk and Gronenberg, 2008).

Functionally, it is noteworthy that dendritic fields of visual input neurons overlap with the projection sites of pigment-dispersing factor-immunoreactive neurons (circadian pacemaker candidates) in the cockroach Leucophaea maderae (Reischig and Stengl, 2002). In the L. maderae, the accessory medulla is the circadian pacemaker controlling locomotor activity rhythms (Reischig and Stengl, 2003). In fruit flies, ablation of the $\mathrm{MB}$ causes individuals to become more active under constant dark conditions (Helfrich-Förster et al., 2002). These data together suggest that the type 1 visual input neurons, which have intimate associations with the accessory medulla (Fig. 3C-E), may relay circadian signals to the MB for controlling locomotor activity rhythms.

Recent findings that both anterior and posterior optic tracts deliver polarization information in the locust S. gregaria (Mappes and Homberg, 2007; Jundi and Homberg, 2010) suggests the possibility that these visual neurons respond to polarized light as well as ordinary visual stimuli in the cockroach, as is demonstrated in a posterior optic tract neuron (Loesel and Homberg, 2001). Future work using controlled visual stimuli (such as color, motion and polarized light stimuli) will be necessary to elucidate the physiological properties of visual input neurons.

The visual input neurons were uniquely characterized by axonal projections to the innermost layer of the calycal neuropil, in which brush-like terminals are linked together. These varicosities were distributed extensively from the proximal region to the tip of the calycal neuropil. Neurons with axons projecting to the Zone II of the calycal neuropil, specialized for visual processing (Strausfeld and Li, 1999a), were not detectable in our intracellular studies. We identified a small interneuron possessing extensive input/output sites in the optic lobe and second-order olfactory centers (Fig. 7), suggesting a role integrating olfactory and visual signals

It is unclear if there is a correlation between the pattern of inputs into the different layers of the calycal neuropil and the pattern of synaptic connections with Kenyon cells. So far, three classes of Kenyon cells have been identified in hemi- and holometabolous insects (reviews: Farris and Sinakevitch, 2003; Farris, 2005; 
Strausfeld et al., 2009). In the cockroach, class I Kenyon cells are the most common type and possess long dendrites that cross layers (Mizunami et al., 1998b; Strausfeld and Li, 1999b). Class II Kenyon cells (class four Kenyon cells, Mizunami et al., 1998b) possess short dendrites and send axons to the $\gamma$ layer which developmentally is the first to emerge (Strausfeld and Li, 1999b; Farris and Strausfeld, 2001). Class III Kenyon cells with dendrites primarily in the small neuropil ventral to the primary calyx take unusual paths in the lobes (Farris and Strausfeld, 2003). The dendritic fields of class III Kenyon cells receive innervations specifically from the tritocerebral tract, which contains afferents from palp mechanosensory and gustatory neurons (Farris, 2008).

In contrast to type 1 uniglomerular PNs, which show cross-layer arrangements of varicosities, visual input neurons show parallel-layer arrangements of varicosities (Figs 3, 4, 8). Given that axons of class II Kenyon cells tend to run in the inner layer and possess short dendrites with unique "clawed endings" (Mizunami et al., 1998b), it is tempting to speculate that, in the innermost layer, axon terminals of visual input neurons specifically synapses onto class II Kenyon cells and those of olfactory PNs specifically synapses onto type I Kenyon cells. To evaluate this possibility, intracellular recordings from extrinsic neurons with dendrites in the $\gamma$ layer are needed.

Physiologically, these visual input neurons exhibited excitatory responses to light-on stimuli and transient inhibitory responses to light-off stimuli. In contrast, olfactory stimuli consistently evoked inhibitory responses in these neurons. This may relate to some form of selective attention in the MB calyces in which visual stimuli are predominantly processed and other sensory signals are held under suppression (Swinderen, 2007).

The two types of olfactory input neurons identified in this study possessed cell bodies in the anterior region of the protocerebrum and supplied axon terminals extensively to the $l$ ho and MB calyces (Figs. 5, 6), both of which are postsynaptic targets of antennal lobe PNs. The olfactory input neurons exhibited excitatory responses to all odors tested, but the response strength differed between odors (Figs. $5,6)$. These results suggest that they have odor-specific, simultaneous modulatory control over the second-order olfactory centers, although transmitters of these neurons are yet unknown. 
Type 1 olfactory input neurons and subtype 1 of type 2 olfactory input neurons lacked axon terminals in zone I of the calycal neuropil (Figs. 5, 6). Furthermore, these neurons lacked any branches in the antero-ventral region of the $l$ ho, where sex pheromone-receptive PNs axon terminals are present. These results suggest that olfactory signals delivered by type 1 uniglomerular PNs, type 2 uniglomerular PNs, and sex-pheromone receptive PNs are processed separately in the olfactory neuropils (Strausfeld and Li, 1999a). This is partly supported by the finding that GABAergic calycal giants, which are thought to affect MB gain control, comprise at least two morphologic subtypes; type 1 supplies axon terminals to zone II-IIIA (Strausfeld and Li, 1999a; Fig. 8D) and type 2 supplies terminals to all zones but provides especially dense termination fields to Zone I (Strausfeld and Li, 1999a; Fig. 8E). To elucidate the functional segregation of olfactory processing in the MB, determination of what kind of odor signal is delivered by type 1 and 2 uniglomerular PNs will be the priority in future studies.

\section{Funding}

This work was supported by the Ministry of Education, Science, Technology, Sports and Culture of Japan (20570066, 23570087 to H.N.).

\section{Acknowledgements}

We thank Dr J. Hill (University of Canterbury) for helpful comments on the manuscript.

\section{References}

Boeckh, J. Ernst, K.D., 1987. Contribution of single unit analysis in insects to understanding of olfactory function. Journal of Comparative Physiology A. 161, 549-565.

Brown, S., Strausfeld, N.J., 2009. The effect of age on a visual learning task in the American cockroach. Learning and Memory 16, 210-223.

de Belle, J.S., Heisenberg M. 1994. Associative odor learning in Drosophila 
abolished by chemical ablation of mushroom bodies. Science 263, 692-695.

Ehmer, B., Gronenberg, W., 2002. Segregation of visual input to the mushroom bodies in the honeybee (Apis mellifera). Journal of Comparative Neurology 451, 362-373.

Erber, J., Masuhr, T., Menzel, R., 1980. Localization of short-term memory in the brain of the bee, Apis mellifera. Physiological Entomology 5, 343-358.

Farris, S.M., 2005. Evolution of insect mushroom bodies: old clues, new insights. Arthropod Structure \& Development 34, 211-234.

Farris, S.M., 2008. Tritocerebral tract input to the insect mushroom bodies. Arthropod Structure \& Development 37, 492-504.

Farris, S.M., Strausfeld, N.J., 2001. Development of laminar organization in the mushroom bodies of the cockroach: Kenyon cell proliferation, outgrowth, and maturation. Journal of Comparative Neurology 439, 331-351.

Farris, S.M., Strausfeld, N.J., 2003. A unique mushroom body structure common to basal cockroaches and to termites. Journal of Comparative Neurology 456, 305-320.

Farris, S.M., Sinakevitch, I., 2003. Development and evolution of the insect mushroom bodies: towards the understanding of conserved development mechanisms in a higher brain center. Arthropod Structure \& Development 32, 79-101.

Farris, S.M., Roberts, N.S., 2005. Coevolution of generalist feeding ecologies and gyrencephalic mushroom bodies in insects. Proceedings Natural Academy of Science USA 102, 17394-173949.

Galizia, C.G., Rössler, W., 2010. Parallel olfactory systems in insects: anatomy and function. Annual Review of Entomology 55, 399-420. 
Gronenberg, W., 2001. Subdivisions of hymenopteraan mushroom body calyces by their afferent supply. Journal of Comparative Neurology 436, 474-489.

Helfrich-Förster, C., Wulf, J., de Belle, J.S., 2002. Mushroom body influence on locomotor activity and circadian rhythms in Drosophila melanogaster. Journal of Neurogenetics 16, 73-109.

Honegger, H-W., Schürmann, F.W., 1975. Cobalt sulphide staining of optic fibres in the brain of the cricket, Gryllus campestris. Cell Tissue Research, 159, 213-225.

Joiner, W.J., Crocker, A., White, B.H., Sehgal, A. 2006. Sleep in Drosophila is regulated by adult mushroom bodies. Nature 441, 757-760.

Jundi, B.E., Homberg, U., 2010 Evidence for the possible existence of a second polarization-vision pathway in the locust brain. Journal of Insect Physiology 56, 971-979.

Krashes, M.J., Keene, A.C., Leung, B., Armstrong, J.D., Waddell, S., 2007. Sequential use of mushroom body neuron subsets during Drosophila odor memory processing. Neuron 53, 103-15.

Kwon, H-W., Lent, D.D., Strausfeld, N.J., 2004. Spatial learning in the restrained American cockroach Periplaneta americana. Journal of Experimental Biology 207, 377-383.

Li, Y., Strausfeld, N.J., 1997. Morphology and sensory modality of mushroom body extrinsic neurons in the brain of the cockroach, Periplaneta americana. Journal of Comparative Neurology 387, 631-650.

Li, Y., Strausfeld, N.J., 1999. Multimodal efferent and recurrent neurons in the medial lobes of cockroach mushroom bodies. Journal of Comparative Neurology 409, 647-663. 
Liu, L., Wolf R., Ernst, R., Heisenberg, M., 1999. Context generalization of Drosphila visual learning requires the mushroom bodies. Nature 400, 753-756.

Loesel, R., Homberg, U., 2001. Anatomy and physiology of neurons with processes in the accessory medulla of the cockroach Leucophaea maderae. Journal of Comparative Neurology 15, 193-207.

Malun, D., Waldow, U., Kraus, D., Boeckh, J., 1993. Connections between the deutocerebrum and the protocerebrum, and neuroanatomy of several classes of deutocerebral projection neurons in the brain of male Periplaneta americana. Journal of Comparative Neurology 329, 143-162.

Mappes, M., Homberg U., 2007. Surgical lesion of the anterior optic tract abolishes polarotaxis in tethered flying locusts, Schistocerca gregaria. Journal of Comparative Physiology 193, 43-50.

McBride, S.M., Giuliani, G., Choi, C., Krause, P., Correale, D., Watson, K., Baker, G., Siwicki, K.K., 1999. Mushroom body ablation impairs short-term memory and long-term memory of courtship conditioning in Drosophila melanogaster. Neuron 24, 967-977.

Mizunami, M., Iwasaki, M., Nishikawa, M. and Okada, R., 1997. Modular structures in the mushroom body of the cockroach. Neuroscience Letters 229, 153-156.

Mizunami, M., Iwasaki, M., Okada, R., Nishikawa, M., 1998a. Topography of modular subunits in the mushroom bodies of the cockroach. Journal of Comparative Neurology 399, 153-161.

Mizunami, M., Iwasaki, M., Okada, R., Nishikawa, M., 1998b. Topography of four classes of Kenyon cells in the mushroom bodies of the cockroach. Journal of Comparative Neurology 399, 162-175.

Mizunami, M., Okada, R., Li, Y., Strausfeld, N.J., 1998c. Mushroom bodies of the 
cockroach: The activity and identities of neurons recorded in freely moving animals. Journal of Comparative Neurology 402, 501-519.

Mizunami, M., Weibrecht, J.M., Strausfeld, N.J., 1998d. Mushroom bodies of the cockroach: Their participation in place memory. Journal of Comparative Neurology $402,520-537$.

Mobbs, P.G., 1982, The brain of the honeybee Apis mellifera L. The connections and spatial organization of the mushroom bodies. Philosophical Transactions of Royal Society of London B. 298, 309-354.

Neder R (1959) Allometrisches Wachstrum von Hirnteilen bei dreiverschieden grossen Schabenarten. Zoologische Jahrbuecher Abteilung für Anatomie und Ontogenie der Tiere 4: 411-464.

Nishikawa, M., Nishino, H., Mizunami, M., Yokohari, F., 1998. Function-specific distribution patterns of axon terminals of input neurons in the calyces of the mushroom body of the cockroach, Periplaneta americana. Neuroscience Letters 245 , 33-36.

Nishino, H., Mizunami, M., 1998. Giant input neurons of the mushroom body: intracellular recording and staining in the cockroach. Neuroscience Letters 246, $57-60$.

Nishino, H, Yamashita, S, Yamazaki, Y, Nishikawa, M, Yokohari, F, Mizunami M., 2003. Projection neurons originating from thermo- and hygrosensory glomeruli in the antennal lobe of the cockroach. Journal of Comparative Neurology 455, 40-55.

Okada, R., Ikeda, J., Mizunami, M., 1999. Sensory responses and movement-related activities in extrinsic neurons of the cockroach mushroom bodies. Journal of Comparative Physiology A 185, 115-129.

Okada, R., Sakura, M., Mizunami, M., 2003. Distribution of dendrites of descending 
neurons and its implications for the basic organization of the cockroach brain. Journal of Comparative Neurology 458, 158-174.

Paulk, A.C., Gronenberg, W., 2008. Higher order visual input to the mushroom bodies in the bee, Bombus impatiens. Arthropod Structure \& Development 37, 443-458.

Pitman, J.L., McGill, J.J., Keegan, K.P., Allada, R., 2006. A dynamic role for the mushroom bodies in promoting sleep in Drosophila. Nature 441, 753-756.

Reischig, T., Stengl, M., 2002. Optic lobe commissures in a three-dimensional brain model of the cockroach Leucophaea maderae: a search for the circadian coupling pathways. Journal of Comparative Neurology 443, 388-400.

Reischig, T. and Stengl, M., 2003. Ectopic transplantation of the accessory medulla restores circadian locomotor rhythms in arrhythmic cockroaches (Leucophaea maderae). Journal of Experimental Biology 206, 1877-1886.

Sakura, M., Mizunami, M., 2001. Olfactory learning and memory in the cockroach Periplaneta americana. Zoological Science 18, 21-28.

Sakura, M., Okada, R., Mizunami, M., 2002. Olfactory discrimination of structurally similar alcohols by cockroaches. Journal of Comparative Physiology A. 188, 787-797.

Sato, C., Matsumoto, Y., Sakura, M., Mizunami, M., 2006. Contextual olfactory learning in cockroaches. NeuroReport 17, 553-557

Schildberger K. 1984. Multimodal interneurons in the cricket brain: properties of identified extrinsic mushroom body cells. Journal of Comparative Physiology 154: 71-79.

Schürmann, F.W., 1974. Bemerkungen zur Funktion der Corpora pedunculata im 
Gehirn der Insekten aus morphologischer Sicht. Experimental Brain Research, 19, 406-432.

Sjöholm, M., Sinakevitch, I., Strausfeld, N.J, Ignell, R., Hansson B.S., 2005. Organization of Kenyon cells in subdivisions of the mushroom bodies of a lepidpteran insect. Journal of Comparative Neurology 491, 290-304.

Strausfeld, N.J., 1976. Atlas of an Insect Brain., Berlin, Springer.

Strausfeld, N.J., Hansen, L., Li Y-S, Gomez, RS., Ito, K., 1998. Evolution, discovery, and interpretations of arthropod mushroom bodies. Learning and memory 5, 11-37.

Strausfeld, N.J., Li, Y., 1999a. Organization of olfactory and multimodal afferent neurons supplying the pedunculus of the cockroach mushroom bodies. Journal of Comparative Neurology 409, 603-625.

Strausfeld, N.J. and Li, Y., 1999b. Representation of the calyces in the medial and vertical lobes of cockroach mushroom bodies. Journal of Comparative Neurology 409, 626-646.

Strausfeld, N.J., Sinkaevitch, I., Brown, S.M., Farris, S.M., 2009. Ground plan of the insect mushroom body: functional and evolutionary implications. Journal of Comparative Neurology 513, 265-291.

Svidersky, V.L., Plotnikova, S.I. 2004. On structural-functional organization of dragonfly mushroom bodies and some general considerations about purpose of these formations. Journal of Evolutionary Biochemistry and Physiology 40, 608-624.

Swinderen, B.V., 2007. Attention-like processes in Drosophila require short-term memory genes. Science 315, 1590-1593.

Tanaka, N.K., Awasaki, T, Shimada, T., Ito, K., 2004. Integration of chemosensory pathways in the Drosophila second-order olfactory centers. Current Biology 23, 
$449-457$.

Tang, S. and Guo, A., 2001. Choice behavior of Drosophila facing contradictory visual cues. Science 294, 1543-1547.

Watanabe, H., Kobayashi, Y., Sakura, M., Matsumoto, Y., Mizunami, M. 2003. Classical olfactory conditioning in the cockroach Periplaneta americana. Zoological Science 20, 1447-1454.

Watanabe H, Nishino H, Nishikawa M, Mizunami M, Yokohari F. 2010. Complete mapping of glomeruli based on sensory nerve branching pattern in the primary olfactory center of the cockroach Periplaneta americana. The Journal of Comparative Neurology 518, 3907-3930.

Wei, H., Jundi B.E., Homberg, U., Sengl, M., 2010. Implementation of pigment-dispersing Factor-Immunoreactive neurons in a standardized atlas of the brain of the cockroach Leucophaea maderae. Journal of Comparative Neurology, $518,4113-4133$.

Yamazaki, Y., Nishikawa, M., Mizunami, M., 1998. Three classes of GABA-like immunoreactive neurons in the mushroom body of the cockroach. Brain Research $788,80-86$. 


\section{Figure Legends}

Fig. 1. Primary brain neuropils in the American cockroach. (A-C) Outlines of neuropils of the right brain hemisphere, viewed anteriorly (A), posteriorly (B), and dorsally (C). (D) Zonal segregation of the calycal neuropil, revealed by axonal projection patterns of extrinsic neurons (modified from figure1 in Strausfeld and Li 1999a). The different zones (I, II, III, and IIIA) are most easily distinguished in the centre of the calyces where the medial and lateral calyces connect to the pedunculus. Scale bars $=100 \mu \mathrm{m}$.

Fig. 2. Projections from the optic lobe and the antennal lobe in the American cockroach. (A-C) Optical sections of seven optic tracts (T1-7) at the level of the anterior-most (A), central (B) and posterior (C) regions of the protocerebrum, viewed anteriorly (frontally). (D-F) Singly-stained interneurons with dendrites in the optic lobe (OL). Their dendritic locations are indicated in figures. A T5 neuron (D) gives rise to axon terminals in the inferior lateral protocerebrum (ILP) and extends a thin axon to the contralateral side (white arrow), whereas two T7 neurons (E, F) have axon terminals in the posterior region of the protocerebrum. (G-I) Axonal projections to the calyces from the optic lobe. In the anterior regions of the lateral $(\mathrm{G})$ and medial calyces $(\mathrm{H})$ and the region where both calyces connect the pedunculus (I), brush-like varicosities are seen in the innermost layer of the calyces. (J-L) Differential labeling of the inner antenno-cerebral tract (magenta) and OL (green) showing the anterior $(\mathrm{G})$, central $(\mathrm{H})$, and posterior $(\mathrm{I})$ regions of the $l$ ho. $(\mathrm{M}, \mathrm{N}) 3 \mathrm{D}$ reconstructions of the $l$ ho, showing the spatial segregation of the optical tracts (green) and axon terminals of almost all populations of uniglomerular PNs (magenta). The broken line indicates the midline of the brain. AL: antennal lobe; AMMC: antennal mechanosensory and motor center; AOtu: anterior optic tubercle; LAL: lateral accessory lobe; SLP: superior lateral protocerebrum. Scale bars $=100 \mu \mathrm{m}$ in A-F, J-N; $50 \mu \mathrm{m}$ in G-I.

Fig. 3. Type 1 visual input neuron. (A, B) The anterior view (A) and dorsal view (B) of the whole neuron, reconstructed two dimensionally from optical sections. (C-E) 
The anterior view of the optic lobe viewed anteriorly showing fine dendritic processes in the lobula (white arrow) and accessory medulla (white arrowhead). C is the same specimen shown in A while D,E are from different individuals. (F, G) Optical sections of calyces in the middle region $(\mathrm{F})$ and the posterior region $(\mathrm{G})$ showing axon terminals distributed almost exclusively in the innermost layer of the calycal neuropil. (H-L) Electrical responses to various sensory stimuli. AL: antennal lobe; aMe: accessory medulla; Me: medulla. V lobe: vertical lobe. Scale bars $=100$ $\mu \mathrm{m}$.

Fig. 4. Type 2 visual input neuron. (A, B) The anterior view (A) and dorsal view (B) of the whole neuron, reconstructed two-dimensionally from optical sections. Dendritic processes were seen in the proximal region of the lobula (arrow), the superior medial protocerebrum (white arrowhead), and the postero-medial region of the protocerebrum (black arrowhead). Axon terminals were distributed in the calyces and the lateral margins of $a-d l$ ho and $p l$ ho (white arrows, A). (C, D) Optical sections of calyces in the middle region (C) and the posterior region (D), showing axon terminals distributed almost exclusively in the innermost layer of the calycal neuropil, although some axon terminals were seen in the outermost layer (white arrow). (E-J) Electrical responses to various sensory stimuli. AL: antennal lobe. V lobe: vertical lobe. Scale bars $=100 \mu \mathrm{m}$.

Fig. 5. Type 1 olfactory input neuron. (A-E) Optical sections of different regions of the protocerebrum, viewed anteriorly, showing fine dendritic processes in the medial protocerebrum (A) and lateral protocerebrum (lower region in B); and varicose axon terminals in the anterior-most region of the $l$ ho (upper region in B) the antero-ventral $l$ ho $(\mathrm{C})$, posterior $l$ ho $(\mathrm{D})$, the neuropil just ventral to the posterior $l$ ho (white arrow, D) and MB calyces (E). Axon terminals do not invade the projection fields of the sex pheromone-processing PNs (marked by broken line, B) or those of type 2 uniglomerular PNs (marked by broken line, C) in the $l$ ho. (F) A dorsal view of the whole neuron, showing the cell body in the antero-dorsal region of the lateral protocerebrum and extensive distribution of axon terminals in the $l$ ho and $\mathrm{MB}$ calyces. (G) Diagram showing the whole neuron reconstructed from optical sections, viewed anteriorly. (H, I) Responses to various sensory stimuli. M lobe: medial lobe; 
V lobe: vertical lobe. a-d lho: antero-dorsal lho; a-v lho: antero-ventral lho; p lho: posterior lho. Scale bars $=100 \mu \mathrm{m}$.

Fig. 6. Type 2 olfactory input neurons. (A) Diagram showing the whole neuron (subtype 1) reconstructed from optical sections, viewed anteriorly. (B-D) Axons from seven cell bodies of type 2 olfactory input neurons (asterisks, B) form a single bundle and supply intermingled axon terminal/dendrite processes in the $l$ ho $(\mathrm{C})$ and the calycal neuropil (D). Asterisks in (D) show a Kenyon cell axon layer. (E,F) Morphologies of subtype 1 (E) and subtype 2 (F) neurons. Branches in the calyces are confined to the zone II-IIIA for subtype 1 and to the zone I for subtype 2. (G) Electrical responses to various odor stimuli in subtype 1 neuron. $\mathrm{M}$ lobe: medial lobe; V lobe: vertical lobe. a-d lho: antero-dorsal lho; a-v lho: antero-ventral lho; $p$ lho: posterior lho. Scale bars $=100 \mu \mathrm{m}$.

Fig. 7. Visual + olfactory input neuron. (A) Diagram showing the whole neuron reconstructed from optical sections, viewed anteriorly. The cell body is located near the type 2 visual input neurons and supplies intermingled axon terminals/dendrites extensively to the optic lobe, lateral horn, and MB calyces. (B) Electrical responses to various odor stimuli. AL: antennal lobe; aMe: accessory medulla; $\mathrm{M}$ lobe: medial lobe; V lobe: vertical lobe. Scale bars $=100 \mu \mathrm{m}$.

Fig. 8. Modality-specific segregation in calyces. (A-F) Anterior views of the anterior region of the medial calyx (outlined by broken lines) which contain type 1 visual input (Fig. 3A), type 1 olfactory input (Fig. 5B), subtype 2 of type 2 olfactory input (Fig. 6F), type 1 calycal giant afferents (Strausfeld and Li, 1999a), type 2 calycal giant afferents (Strausfeld and Li, 1999a), and type 1 uniglomerular PN with dendrites in the glomerulus E01 (Strausfeld and Li, 1999a; Watanabe et al. 2010; Fig. $6 F)$. Solid lines indicate the border between the calycal neuropil and Kenyon cell axon layer. (G) A diagram summarizing the projection patterns of different types of calycal input neurons. Single asterisk indicates neurons reported by Strausfeld and Li (1999a). Scale bars $=50 \mu \mathrm{m}$. 


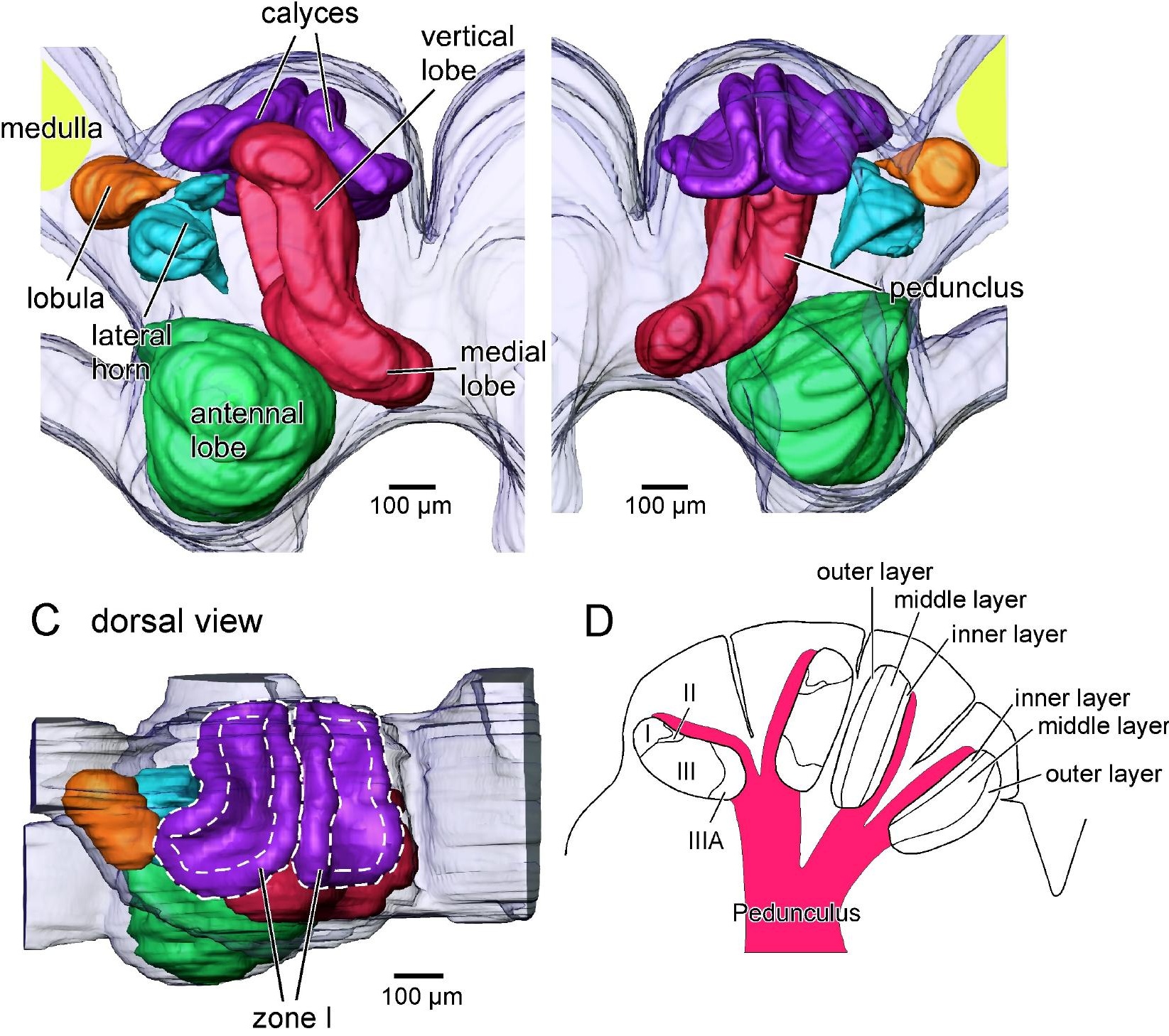




\section{B}

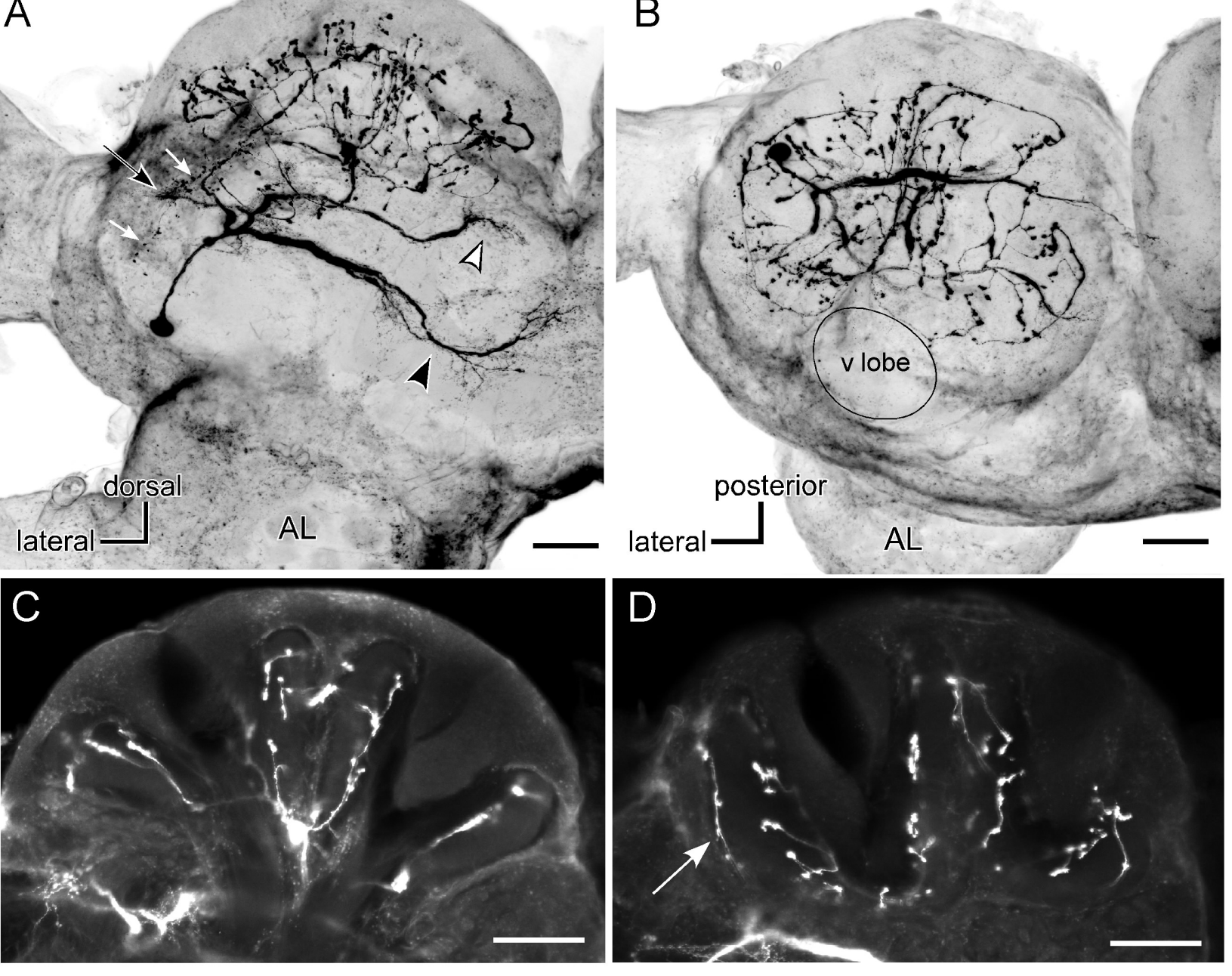

E 1st $\quad \longleftarrow$ light on light off

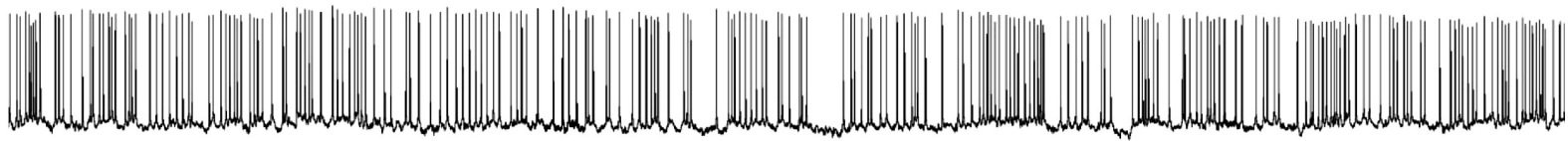

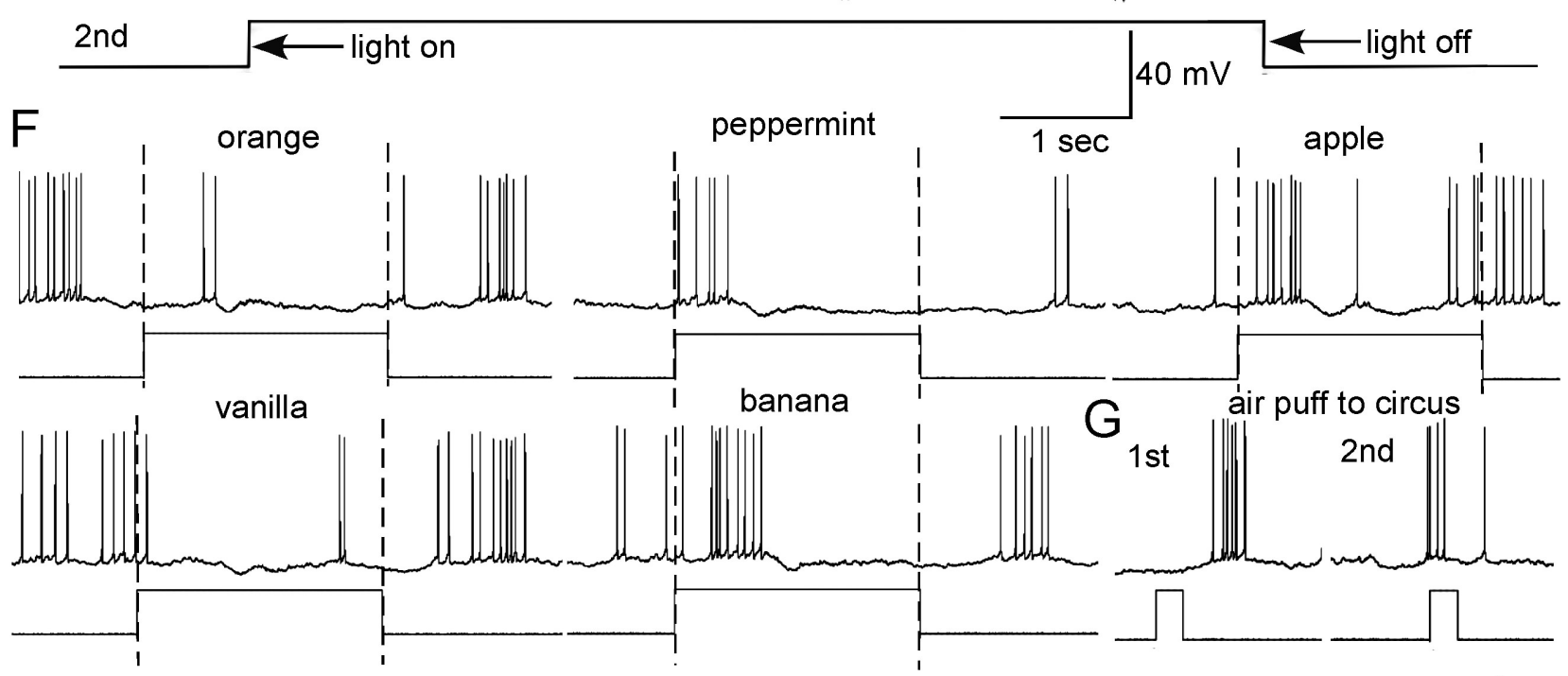




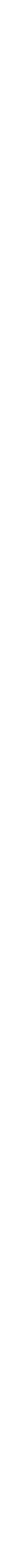




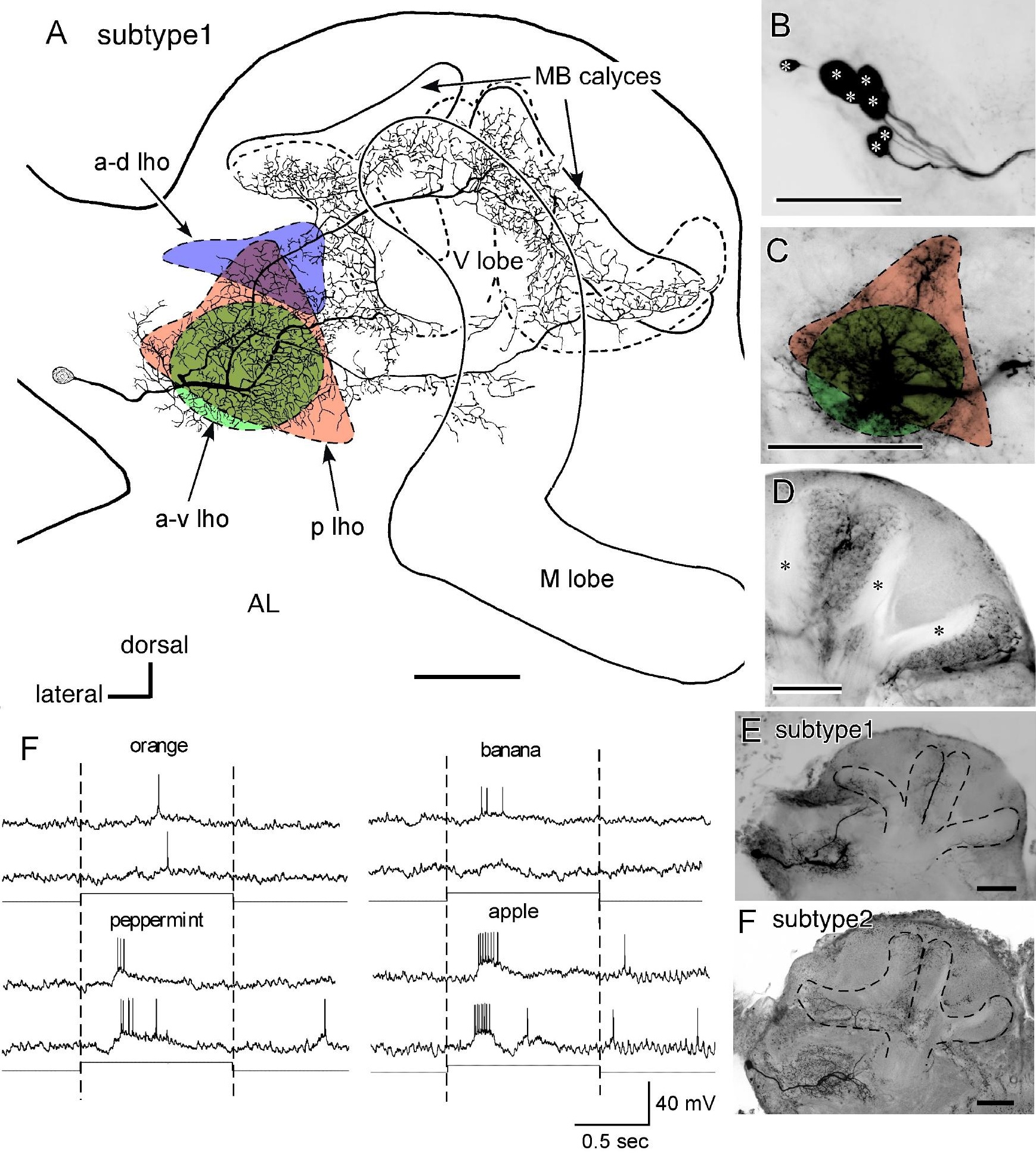


A medulla

A
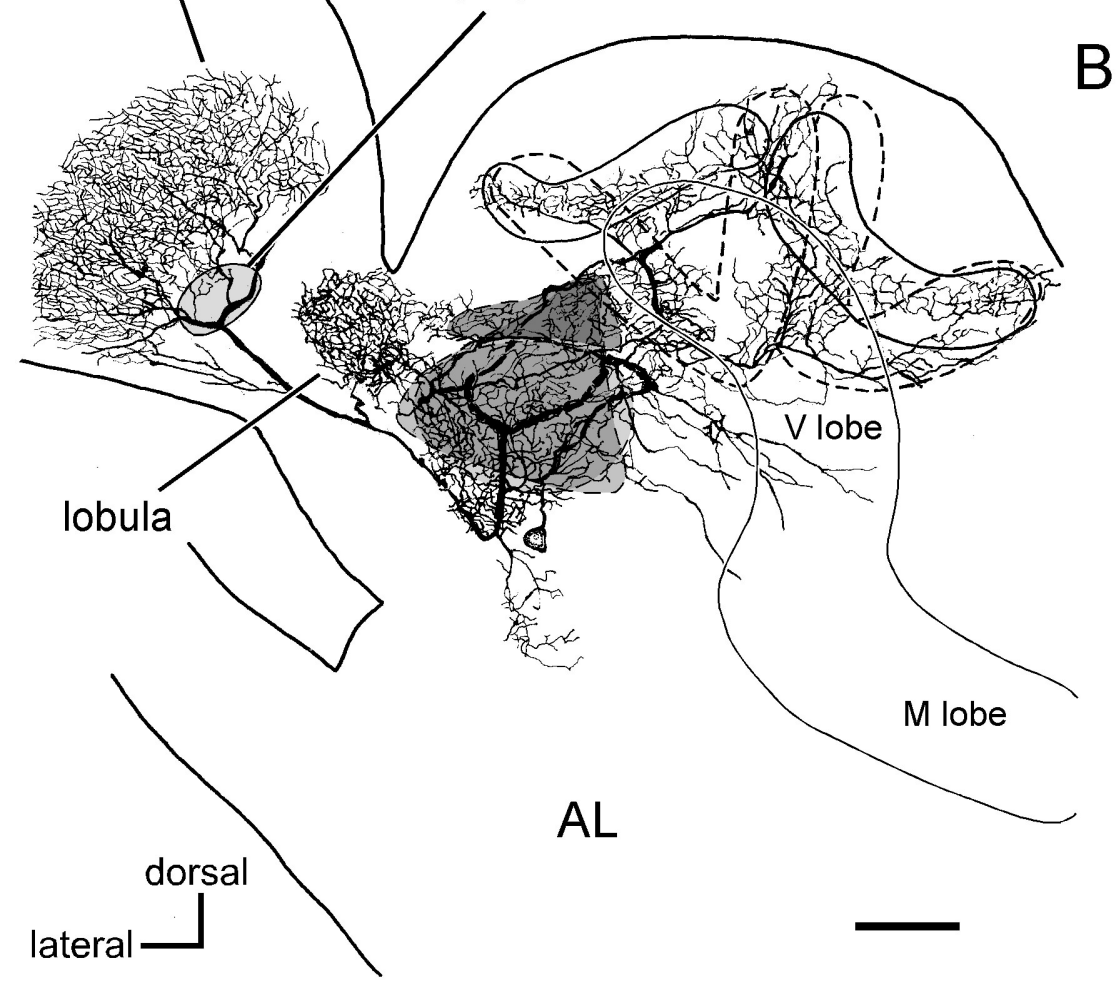

$\mathrm{AL}$
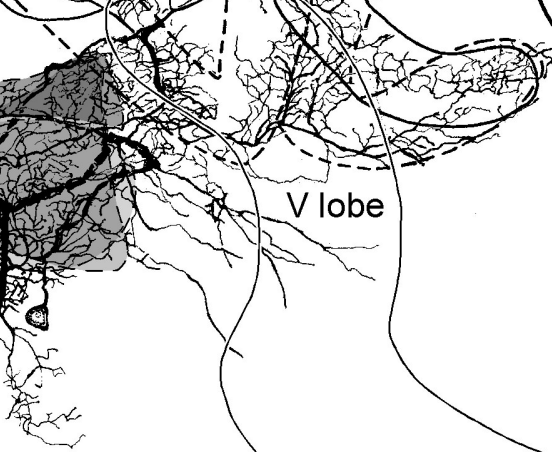

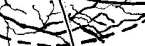

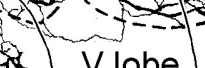

V lobe
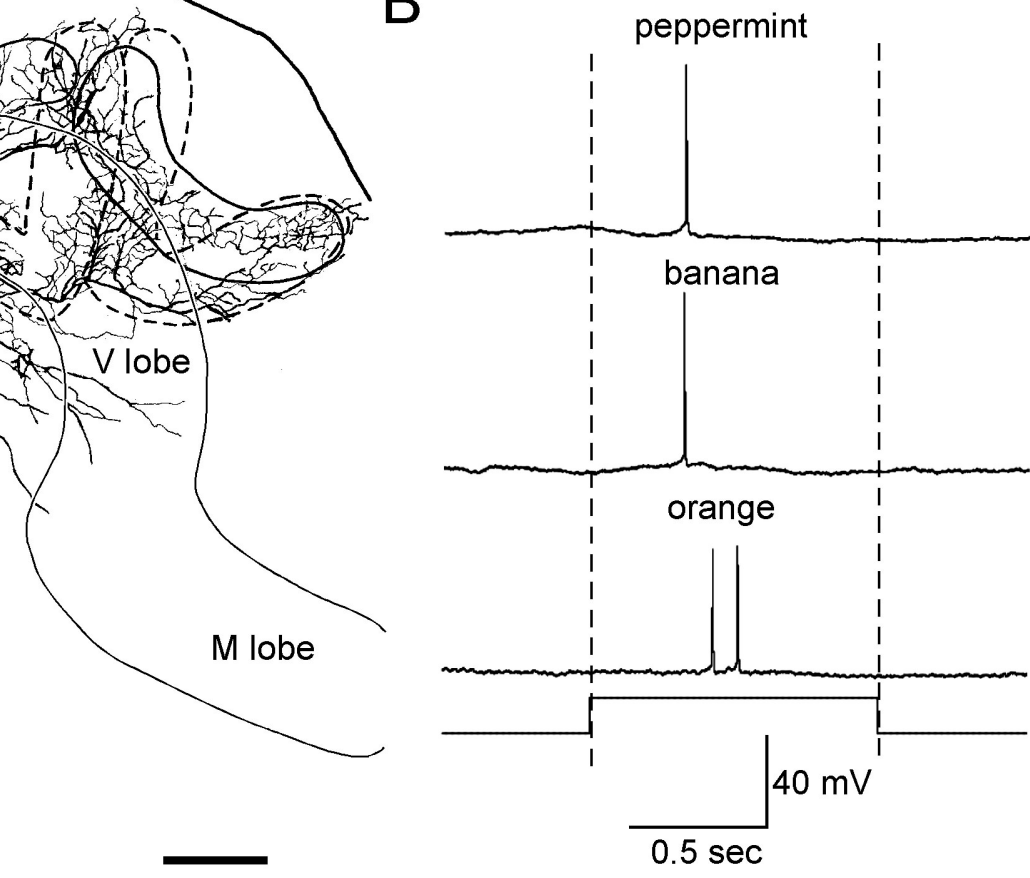

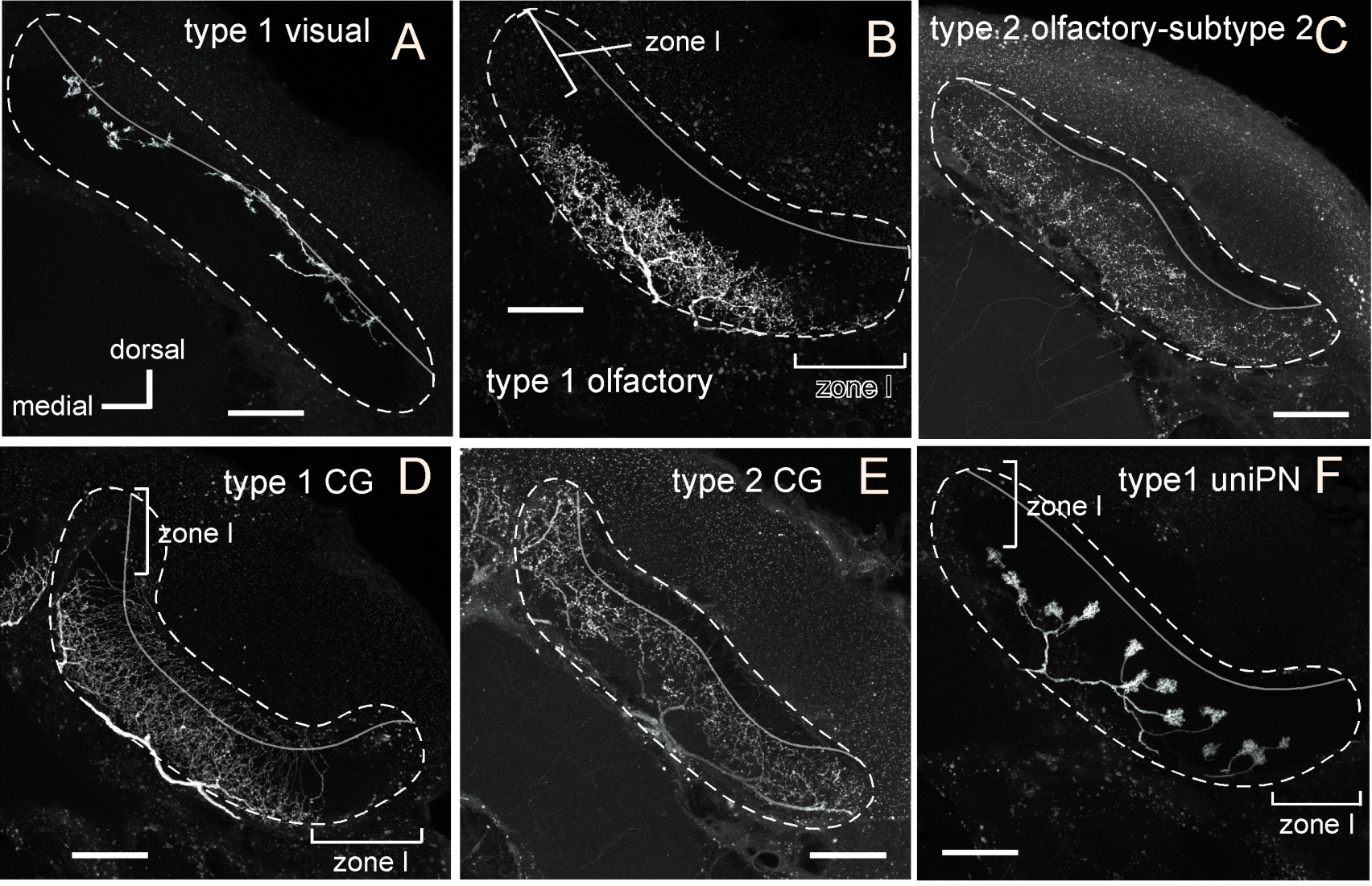

G
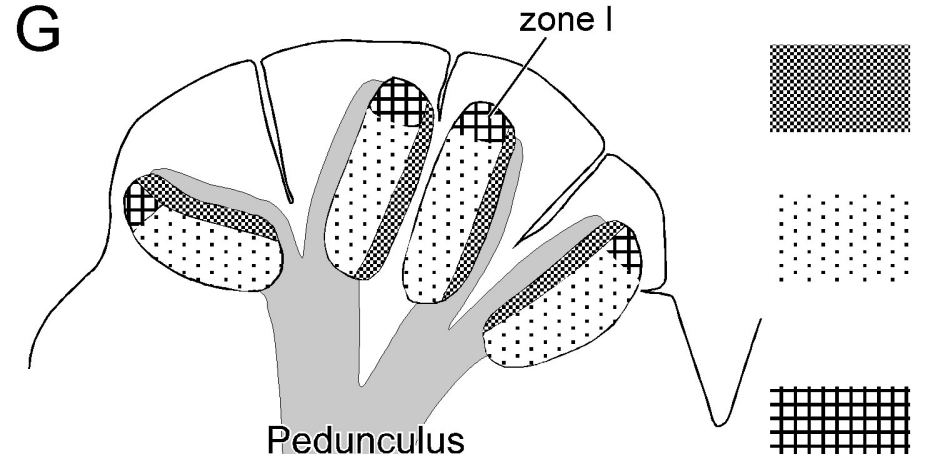

visual input neurons (Figs. 3,4)

type 1 giant afferent*,

type 1 uniglomerular $\mathrm{PN}^{*}$

type 1 olfactory input (Fig. 5)

type 2 olfactory input-subtype 1 (Fig. 6)

Pedunculus

\#姆e 2 uniglomerular $\mathrm{PN}^{*}$

艮的 2 giant afferent*

册册 type 2 olfactory input-subtype 2 (Fig. 6) 